\title{
A Study of Lower Lung Tuberculosis
}

\author{
Dr. P. Chandrasekhara ${ }^{1}$, Dr. Mohsin Aslam ${ }^{2}$, Dr. S. Koshy ${ }^{3}$ \\ I(MD, Professor and Head of Department, Department of Medicine, MVJ Medical College and Research \\ Hospital, India). \\ 2(Post Graduate in Medicine, MVJ Medical College and Research Hospital, India). \\ 3(Post Graduate in Medicine, MVJ Medical College and Research Hospital, India).
}

\begin{abstract}
When tuberculosis is confined to the lower lung fields, it often masquerades as pneumonia and the correct diagnosis gets delayed. Early diagnosis and treatment helps in the prevention of complications, a proper understanding of clinical, radiological, and bacteriological presentations, as well as treatment outcome of this disease entity is of crucial importance. This study was taken up to study the clinical features of lower lung field tuberculosis in a rural tertiary care centre in South India. From August 2011 to July 2012, 40 cases of Lower lung field Tuberculosis admitted to medical wards were studied. 24(60\%) were males, 28(70\%) were $>40$ age, $38(95 \%)$ had respiratory symptoms in the form of cough and scanty expectoration, 30(75\%) had mild to moderate fever, 21(52.5\%) had weight loss, 4(10\%) had pleuritic pain, 6(15\%) had scanty hemoptysis. Both lungs were equally involved with slight preponderance to right lung, 6(15\%) had bilateral involvement. Predisposing conditions - 14(35\%) diabetic, 4(10\%) past history of PTB and 2(5\%) had HIV. 2(5\%) were sputum negative had unresolving pneumonia which responded to ATT. Conclusion: Tuberculosis should be considered when lower lung fields are involved, in elderly, Diabetics, HIV, immunocompromised and when the radiologic picture suggests unresolved pneumonia. Further investigation needed to confirm the Diagnosis of Lower Lung Tuberculosis. Response is similar as apical tuberculosis.
\end{abstract}

Key Words: Pulmonary Tuberculosis, Lower Lung Field Tuberculosis, Unresolving Pneumonia, ATT.

\section{Introduction}

The post-primary pulmonary tuberculosis (TB) seen in adults, is a disease located predominantly in upper lobes. Since Laennec's era, lower lung field TB was considered a rarity. In fact, Laennec himself opined that TB hardly ever developed in middle or lower lobes of the lungs ${ }^{1}$. In 1866, Kidd stated that "apex of lower lobe is very prone to tubercular disease and may be attacked before the apex of the upper lobe"2. Fowler stated that "the upper and posterior part of the lower lobe is a spot only second in point of vulnerability to the apex itself ${ }^{\prime 3}$. When tuberculosis is confined to the lower lung fields, it often masquerades as pneumonia and the correct diagnosis may not be considered for a prolonged time4. Therefore, a high index of suspicion is the key to the diagnosis of lower lung field TB.

\subsection{DEFINITION}

Lower lung field tuberculosis is defined as "Tuberculous disease found below an imaginary line traced across the hila and including the parahilar regions on a standard posterior-anterior chest $\mathrm{x}$-ray without concomitant involvement of upper lobe." ${ }^{4}$

Anatomically, this includes the right middle lobe and lingula, in addition to the lower lobes.

\subsection{INCIDENCE}

The incidence of lower lung field TB in studies reported from India has been observed to be higher than that reported in western studies. (Table 1)

This may be due to the fact that a majority of Indians tie their clothes (women their sari and men their loin cloth) tightly around the upper abdomen and this results in impaired movement of diaphragm. This theory has been substantiated by Viswanathan ${ }^{5}$, who studied the diaphragmatic movements on the radiographic screening in subjects accustomed to tight lacing around their waists. It has been suggested that the resultant impaired movement of diaphragm leads to costal type of breathing (as in females), which leads to decreased ventilation, retarded blood flow in lower lung fields, thus making them more vulnerable to tuberculosis. ${ }^{5,6}$

\subsection{PATHOGENESIS}

Besides the above cited plausible mechanisms, the most common pathogenetic mechanism of lower lung field tuberculosis is the ulceration of a bronchus by a lymph node affected by tuberculosis with spillage of tubercular material into the bronchus. Most authors have proposed that, lower lung field tuberculosis occurs as a continuum of primary tuberculosis or soon after, in the post primary phase ${ }^{7,8}$. 


\subsection{ASSOCIATED CONDITIONS}

1. Diabetes mellitus

2. Pregnancy

3. HIV

4. Advanced age

5. Use of corticosteroids

6. Kyphoscoliosis

7. Silicosis ${ }^{7,9,10-12}$.

\section{Objectives Of The Study}

To study the clinical profile of lower lung field tuberculosis in a tertiary care centre in rural South India.

\section{Materials And Methods}

From August 2011 to July 2012, 40 cases of Lower lung field Tuberculosis admitted to medical wards were studied.

\subsection{INCLUSION CRITERIA}

Subjects were selected on the basis of disease confined to one or both lower lung fields on posteroanterior views of chest $\mathrm{x}$-rays.

Pulmonary tuberculosis was diagnosed when at least one of the following criteria was met in patients with lower lobe involvement:

1. Sputum AFB positive - direct/concentrated method/culture/BAL

2. Chest $\mathrm{x}$-ray/CT scan interpreted as pulmonary tuberculosis plus clinical and radiographic improvement with anti- tuberculous medications 13.

\subsection{EXCLUSION CRITERIA}

1. Cases of either ipsilateral or contralateral involvement of both upper and lower lung fields.

2. Pleural effusion and thickening, unless associated with parenchymal lesions in the area involved.

\section{Results}

40 consecutive cases of lower lung tuberculosis were included for the study randomly of which 24 $(60 \%)$ were males. $28(70 \%)$ were $>40$ years of age (Table 2$)$

Various risk factors noted in the study were Diabetes seen in $14(35 \%)$ of patients, $12(30 \%)$ were elderly, $7(17.5 \%)$ were alcoholics, $4(10 \%)$ had previous history of pulmonary tuberculosis and $2(5 \%)$ were HIV positive cases (Fig. 1).

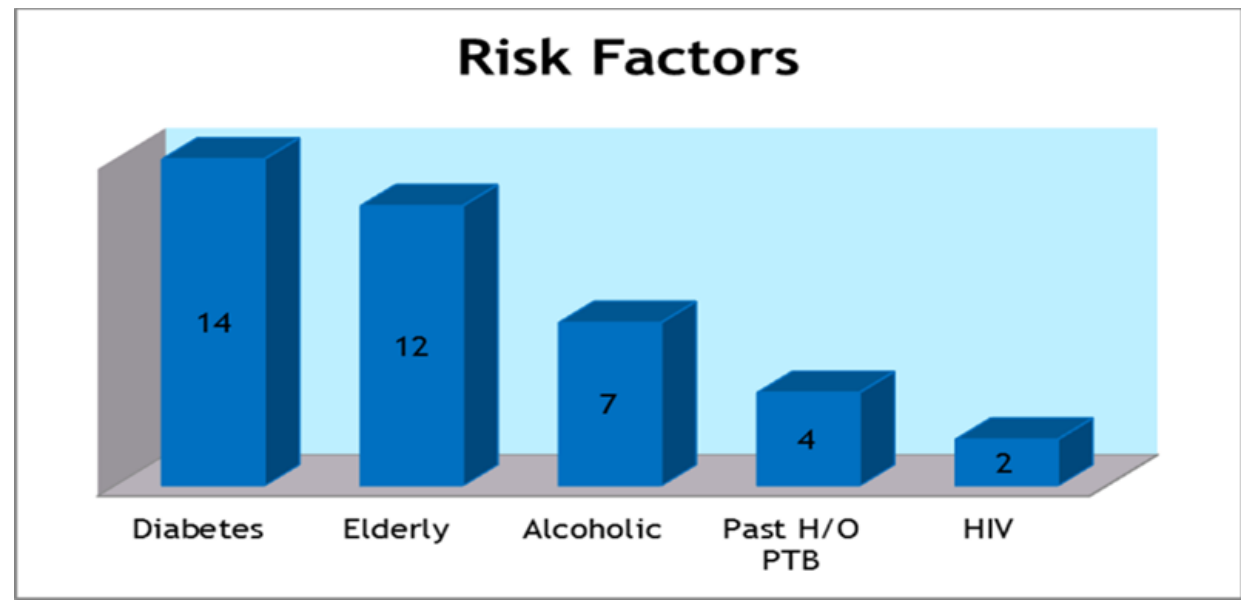

Figure 1: Risk factors for TB

$38(95 \%)$ had respiratory symptoms in the form of cough and scanty expectoration, $30(75 \%)$ had mild to moderate grade fever, $21(52.5 \%)$ had weight loss, 4 (10\%) had pleuritic pain, $6(15 \%)$ had hemoptysis (Fig. 2). 


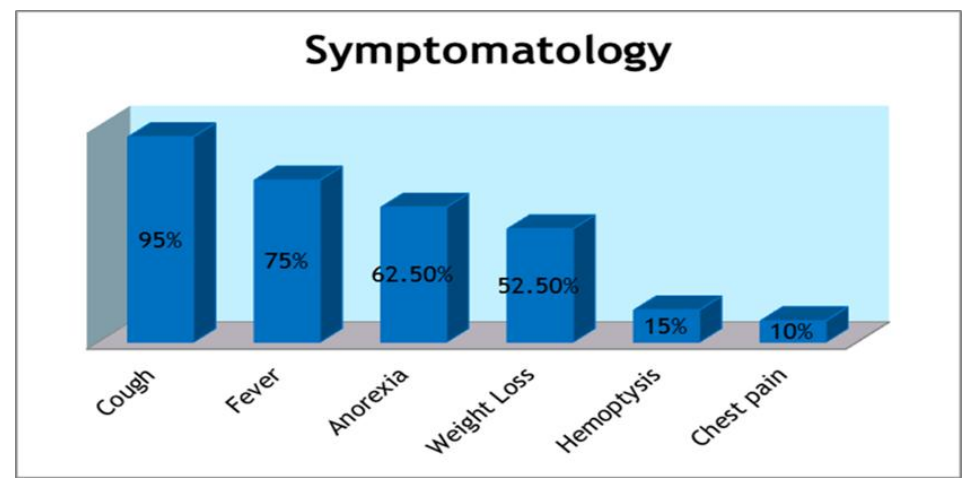

Figure 2: Symptomatology

Main radiological presentation was patchy opacities seen in $18(45 \%)$ of patients, homogeneous consolidation seen in $14(35 \%)$ of patients, cavitation was seen in $7(17.5 \%)$ of patients, nodular opacities in 5 (12.5\%). 4 (10\%) patients had para pneumonic effusion (Fig. 3). 18 (45\%) had right lung involvement, 16 (40\%) had left lower lobe involvement, $6(15 \%)$ had bilateral involvement.

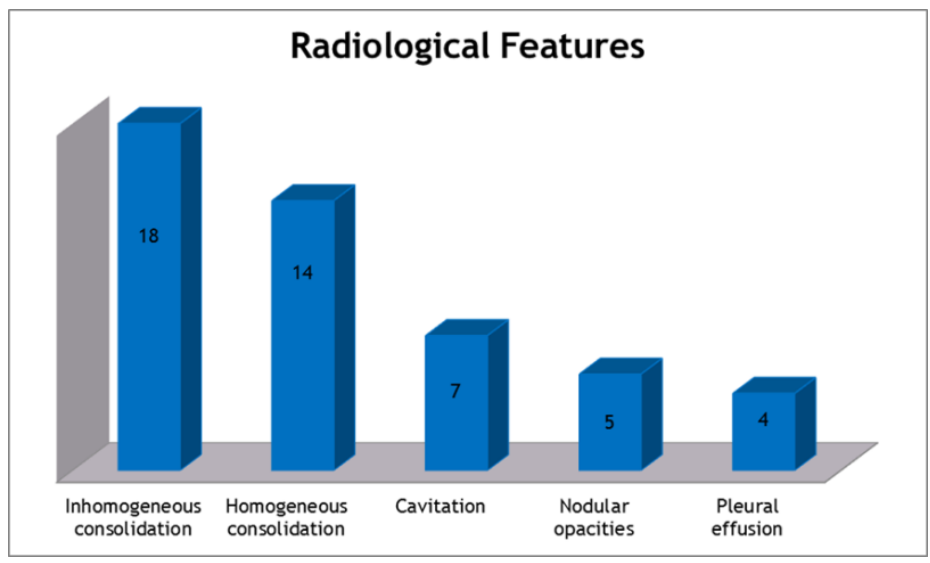

Figure 3: Radiological Presentation

Sputum smear for AFB was positive in 25 (62.5\%) cases, 6 (15\%) cases had BAL positive for AFB, 6 $(15 \%)$ cases were diagnosed based on CT findings suggestive of TB and $2(5 \%)$ were sputum negative and had unresolving pneumonia which improved on treatment. Hilar lymph node biopsy showed caseating tubercular granuloma in 1 (2.5\%) case (Fig. 4).

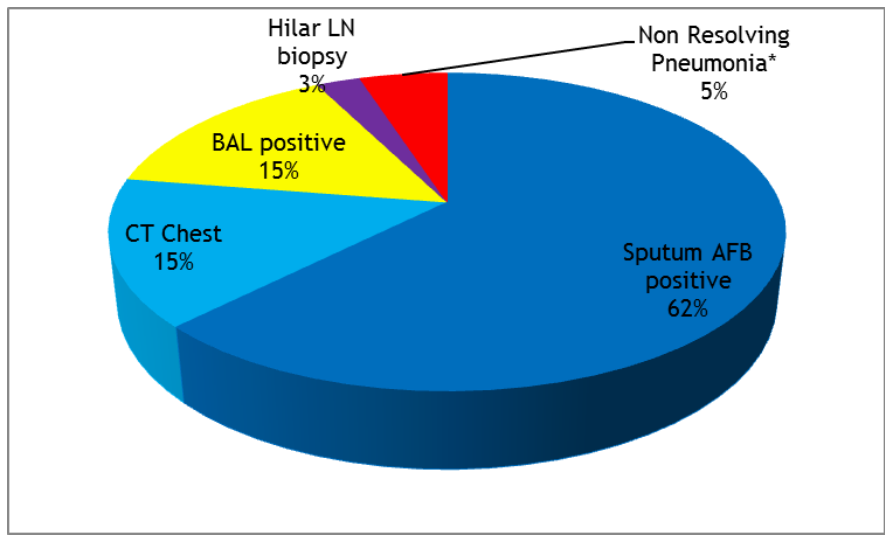

Figure 4: Diagnosis of lower lung field TB

Response to treatment was good in all cases and no deaths were reported.

\section{Discussion}

In most studies $7,10,14,15$, female preponderance and predilection for patients under the age of 40 years has been reported. Tripathy and Nanda ${ }^{16}$ did not find a similar distribution in their study. Chang et al ${ }^{9}$ have 
observed that lower lung field TB is no longer a disease of young. In our study, we had male preponderance and more number of patients above the age of 40 years (Table 3). The possible reason for this is, as our study was done in a rural setup, females do not present early in the disease and by the time they present the disease is extensively involved. More elderly population seek medical help.

Average duration of symptoms at presentation was around 1 month, 32(80\%) of patients presented within 1 month. Most series report symptoms for less than 6 months ${ }^{1,7,9}$. Tripathy and Nanda ${ }^{16}$ have observed that around $20 \%$ of patients have reported within 2 weeks and $70 \%$ of patients within 6 months in their series of 36 cases.

Cough with expectoration was seen in $95 \%$ of patients, mild to moderate fever in $75 \%$ of patients, pleuritic chest pain in $10 \%$ cases, hemoptysis in $15 \%$ and weight loss in $52.5 \%$ of patients (Table 4). Cough with variable amount of sputum is the most frequent symptom ${ }^{5,7}, 16$. Mathur et al ${ }^{17}$ reported cough in $100 \%$ cases. The general toxic manifestations of TB infection such as fever, chills, malaise weakness and anorexia are also frequently seen. Segarra et al $^{7}$ reported these symptoms in about $40 \%$ of their cases whereas Tripathy and Nanda ${ }^{16}$ reported them in $86 \%$ of their cases.

Right lower lung field involvement seen in18 (45\%) of cases, left lower lung involvement was seen in $16(40 \%)$ of cases and bilateral lower lung involvement in $6(15 \%)$ of cases (Table 5). More than half of the cases of lower lung field TB have right lung involvement whereas one-third have left lung involvement. Bilateral lesions are reported in $10 \%$ of the cases ${ }^{8,10,16}$. Reasons for higher prediction of infection in the right lung are not well understood, though, more common right sided infection might be due to anatomical variations. The radiographic findings in lower lung field TB differs significantly from those found in upper lobe disease ${ }^{6}$. The most frequent radiographic finding is consolidation, which is more confluent and extensive than that found in upper lobes $\mathrm{TB}^{18}$.

Cavitary lesions are also frequently seen, which may be single or multiple and may lie within an area of consolidation $1,{ }^{9}$. The presence of tension cavities (thin walled with fluid) is also a radiological feature of lower lung field $\mathrm{TB}^{7}, 16,19,20$. Other radiological features include evidence of atelectasis or solitary mass with intrathoracic lymphadenopathy.

\section{Conclusion}

Lower lobe TB is frequently confused with the more common pneumonias. Tuberculosis should be considered in our country, in diabetics, elderly, HIV, immunocompromised and when the radiologic picture suggests unresolved lower lobe pneumonia, abscess, bronchiectasis or chronic pneumonitis. The early diagnosis of lower lung field tuberculosis is important for prevention of severe sequelae. Repeated and extensive investigations are required to confirm diagnosis in doubtful cases. Induced sputum and careful detailed smear examination - direct smear, concentration, culture, are often necessary to secure bacteriologic proof of tuberculosis. Fibreoptic bronchoscopy provides a higher diagnostic yield than sputum examination, especially in patients who present with radiographic findings of consolidation, collapse or solitary mass. CT scan should be considered in some cases when deemed necessary Therapeutic trial of ATT in unresolved pneumonia may help to diagnose lower lobe tuberculosis. Response to therapy is good in all cases.

\section{Acknowledgement}

We would like to express our sincere thanks to the Medical Superintendent, MVJ Medical College and Research Hospital for giving us the permission to perform this study and constant encouragement in carrying out this study.

\section{References}

[1]. Laennec RH. Treatise on the diagnosis and treatment of the diseases of the chest. New York. Hafner Publishing; 1962.

[2]. Kidd P. Basic tuberculosis phthisis. Lancet 1886;2:616.

[3]. Fowler JK. The localization of lesions of phthisis. London: J and A Churchill; 1888.

[4]. Herbert W. Berger, Margarito G. Gramdo. Lower lung field tuberculosis. Chest 1974:65:522-6

[5]. Viswanathan R. Tuberculosis of the lower lobe. Br Med J 1936;2:1300-2.

[6]. Reisner D. Pulmonary tuberculosis of the lower lobe. Arch Intern Med 1935;56:258-80.

[7]. Segarra F, Sherman DS, Rodriguez-Aguero J. Lower lung field tuberculosis. Am Rev Respir Dis 1963;87:37-40.

[8]. Parmer MS. Lower lung field tuberculosis. Am Rev Respir Dis 1967;96:310-3.

[9]. Chang SC, Lee PY, Perng RP. Lower lung field tuberculosis. Chest 1987;91:230-2.

[10]. Sokoloff MJ. Lower lobe tuberculosis. Radiology 1940;34:589-94.

[11]. Fernandez MZ, Nedwicki EG. Lower lung field tuberculosis. Mich Med 1969,68:31-5.

[12]. Morris JT, Seaworth BJ, McAllister CK. Pulmonary tuberculosis in diabetes. Chest 1992;102:539-41.

[13]. World Health Organization. Treatment of tuberculosis: Guidelines for National Programs. WHO /CDS/TB/2003. p.313.

[14]. Dunham K, Norton W. Basal tuberculosis. JAMA 1927;89:1573-5.

[15]. Ross EL. Tuberculosis in nurses-a study of the disease in 60 nurses admitted to Manitoba sanatorium. Can Med Assoc $\mathrm{J}$ 1930;22:347-54.

[16]. Tripathy SN, Nanda CN. Lower lung field tuberculosisin adults. J Assoc Physicians India 1970;18:999-1008.

[17]. Mathur KC, Tanwar KL, Razdan IN. Lower lung field tuberculosis. Indian J Chest Dis 1974;16:31-41. 
[18]. Chang SC, Lee PY, Perng RP. The value of roentgenographic and fiberbronchoscopic findings in predicting outcome of adults with lower lung field tuberculosis. Arch Intern Med 1991;151:1581-3.

[19]. Perez-Guzman C, Torres-Cruz A, Villarreal-Velard H, Salazar-Lezama MA, Vargas MH. Atypical radiological images of pulmonary tuberculosis in 192 diabetic patients: a comparative study. Int J Tuberc Lung Dis 2001;5:455-61.

[20]. Kobashi Y, Matsushima T. Clinical analysis of recent lower lung field tuberculosis. J. Infect Chemother 2003;9:272-5.

[21]. Zuber Ahmad, M Shoaib Zaheer. Lower lung field tuberculosis - A clinical study. JIACM 2003; 4(2): 116-20.

[22]. Hamilton CE, Fredd H: Lower lobe tuberculosis: A review. JAMA 105:427-430, 1935.

\section{TABLES}

Table 1: Incidence of lower lung field tuberculosis

\begin{tabular}{|c|c|c|c|}
\hline Author & $\begin{array}{c}\text { Total Population } \\
\text { Studied }\end{array}$ & $\begin{array}{c}\text { Subjects with } \\
\text { Lower Lung Field } \\
\text { Tuberculosis }\end{array}$ & Incidence \\
\hline Hamilton et al (1935) & 349 & 10 & $3 \%$ \\
\hline Viswanathan (1936) & 638 & 41 & $6.4 \%$ \\
\hline Tirona (1940) & 14,337 & 11 & $0.08 \%$ \\
\hline Segarra et al (1963) & 10,962 & 94 & $0.87 \%$ \\
\hline Parmar (1967) & 1,455 & 50 & $3.4 \%$ \\
\hline Tripathy and Nanda (1970) & 707 & 36 & $5.1 \%$ \\
\hline Mathur et al (1974) & 5,072 & 32 & $0.63 \%$ \\
\hline Berger et al (1974) & 386 & 27 & $7 \%$ \\
\hline Khan et al (1977) & 88 & 6 & $6.8 \%$ \\
\hline Zuber Ahmad et al (2003) & 4,430 & 465 & $10.5 \%$ \\
\hline
\end{tabular}

Table 2: Results - Age and Sex Distribution

\begin{tabular}{|l|c|c|c|}
\hline & Age $<40$ Years & Age $>40$ Years & Total \\
\hline No. of males & $5(12.5 \%)$ & $19(47.5 \%)$ & $24(60 \%)$ \\
\hline No. of females & $7(17.5 \%)$ & $9(22.5 \%)$ & $16(40 \%)$ \\
\hline Total Patients & $12(30 \%)$ & $28(70 \%)$ & $40(100 \%)$ \\
\hline
\end{tabular}

Table 3: Comparison of age and sex distribution in different studies

\begin{tabular}{|c|c|c|c|c|}
\hline Authors & Males & Females & Age $<\mathbf{4 0}$ years & $>$ 40 years \\
\hline Zuber Ahmad & 247 & 218 & 384 & 81 \\
\hline Segarra et al & 26 & 68 & 84 & 10 \\
\hline Parmar & 23 & 27 & 50 & - \\
\hline Reisner & 6 & 28 & 31 & 3 \\
\hline Berger et al & 17 & 10 & 16 & 11 \\
\hline Sokoloff & 6 & 18 & 3 & 3 \\
\hline Ossen & 2 & 12 & 4 & - \\
\hline Tirona & 9 & 2 & 8 & 3 \\
\hline Present study & $\mathbf{2 4}$ & $\mathbf{1 6}$ & $\mathbf{1 2}$ & $\mathbf{2 8}$ \\
\hline
\end{tabular}

Table 4: Symptomatology in different studies

\begin{tabular}{|c|c|c|c|c|c|}
\hline Authors & Cough & Fever & $\begin{array}{c}\text { Chest } \\
\text { Pain }\end{array}$ & Hemoptysis & Weight Loss \\
\hline $\begin{array}{c}\text { Viswanathan } \\
(41)\end{array}$ & $41(100 \%)$ & $6(15 \%)$ & $7(17 \%)$ & - & - \\
\hline Berger et al (27) & $25(92.6 \%)$ & $22(82 \%)$ & $16(59 \%)$ & $12(44 \%)$ & $12(44 \%)$ \\
\hline Sokoloff (24) & $13(54 \%)$ & $7(29 \%)$ & $2(8 \%)$ & - & - \\
\hline $\begin{array}{c}\text { Tirona (11) } \\
\text { Hamilton et al } \\
(10)\end{array}$ & $10(100 \%)$ & $2(20 \%)$ & $8(80 \%)$ & $5(50 \%)$ & - \\
\hline \begin{tabular}{c} 
Present study \\
\hline
\end{tabular} & $\mathbf{3 8 ( 9 5 \% )}$ & $\mathbf{3 0 ( 7 5 \% )}$ & $\mathbf{4 ( 1 0 \% )}$ & $\mathbf{6 ( 1 5 \% )}$ & $\mathbf{2 1 ( 5 2 . 5 \% )}$ \\
\hline
\end{tabular}


Table 5: Site of lesion

\begin{tabular}{|c|c|c|c|}
\hline Authors & Right Lower Lobe & Left Lower lobe & $\begin{array}{c}\text { Bilateral Lower } \\
\text { Lobe }\end{array}$ \\
\hline Viswanathan & 34 & 4 & 3 \\
\hline Berger et al & 12 & 12 & 3 \\
\hline Sokoloff & 14 & 5 & 5 \\
\hline Tirona & 8 & 2 & 1 \\
\hline Segarra et al & 55 & 24 & 15 \\
\hline Present study & $\mathbf{1 8}$ & $\mathbf{1 6}$ & $\mathbf{6}$ \\
\hline
\end{tabular}

